\title{
Prescribing behaviour of village doctors under China's New Cooperative Medical Scheme ${ }^{\text {is }}$
}

\author{
Xiaoyun Sun ${ }^{\mathrm{a}, *}$, Sukhan Jackson ${ }^{\mathrm{b}}$, Gordon A. Carmichael ${ }^{\mathrm{c}}$, Adrian C. Sleigh ${ }^{\mathrm{c}}$ \\ ${ }^{a}$ Health Department of Shandong Province, Division of Maternal E Child Health and Community Health, 9 Yan Dong Xin Road, Jinan, Shandong 250014, China \\ ${ }^{\mathrm{b}}$ School of Economics, The University of Queensland, St Lucia, Brisbane, Queensland 4072, Australia \\ ${ }^{\mathrm{c}}$ National Centre for Epidemiology and Population Health, The Australian National University, Canberra, ACT 0200, Australia
}

\section{A R T I C L E I N F O}

\section{Article history:}

Available online 1 April 2009

\section{Keywords:}

China

Village doctor

New Cooperative Medical Scheme

Prescribing behaviour

Antibiotics

Health insurance

Rural

\begin{abstract}
A B S T R A C T
In 2003, China introduced a new community-based rural health insurance called the New Cooperative Medical Scheme (NCMS). In 2005, to assess the NCMS effects on village doctors' prescribing behaviour, we compared an NCMS county and a non-NCMS county in Shandong Province. We collected information from a representative total of 2271 patient visits in 30 village health stations ( 15 per county).

The average number of drugs prescribed (4.6 in the NCMS county vs. 3.1 in the non-NCMS county) and use of antibiotics ( $72.4 \%$ vs. $59.3 \%$ ) and injections (65.1\% vs. $56.3 \%$ ) were high in both counties, and higher in the NCMS county. Within NCMS villages, prescribing for insured vs. uninsured patients showed a similar pattern with more drugs, antibiotics and injections for those insured. Overall, for NCMS patients, the prescription excess was about equal in value to their $20 \%$ fee discount.

We conclude that over-prescribing is common in villages and worse with NCMS health insurance, raising concerns for health service quality and drug-use safety. We propose that the NCMS should be redesigned with incentives for service quality improvement. A stricter regulatory environment for doctors' prescriptions is needed in rural China to counter irrational drug use.
\end{abstract}

(c) 2009 Elsevier Ltd. All rights reserved.

\section{Introduction}

In 2003, the Chinese government launched a New Cooperative Medical Scheme (NCMS) to help finance rural healthcare. The NCMS began in 305 pilot counties and is expected to cover all rural areas by 2010 . Such health insurance is designed to reduce catastrophic medical payments (Sun, Jackson, Carmichael, \& Sleigh, 2009) but it could also encourage opportunistic behaviour from healthcare providers, such as over-prescribing drugs. Here we compare drug prescribing in village health stations in areas with and without the NCMS.

Current reforms of the rural health finance in China are related to other economic reforms in China over the last 25 years. The abolition of agricultural communes in 1982 led to collapse of community-funded healthcare for farmers. Market-oriented health sector reforms followed with privatization of rural healthcare

\footnotetext{
is The Ford Foundation International Fellowship Program supported Xiaoyun Sun for her PhD study; the National Centre for Epidemiology and Population Health of the Australian National University, and an Australian Research Council Large Research Grant (No. A00105533), added support for field work.

* Corresponding author. Tel.: +86 13553180219; fax: +8653167876166.

E-mail address: sxysdcn@yahoo.com.cn (X. Sun).
}

providers (Liu, 2004; Meng, Liu, \& Shi, 2000). Government spending fell from $36.2 \%$ of total health expenditure in 1980 to $15.2 \%$ in 2002 (Centre for Health Statistics and Information Ministry of Health, 2004). Farmers are not eligible for the national basic medical insurance scheme for urban employees set up in 1998. Now most rural residents pay out-of-pocket for medical care which is provided on a fee-for-service basis.

In 1994, the Chinese government piloted a rural communitybased medical scheme, pooling risk for a township of $10,000-$ 50,000 people. Many of these early insurance schemes closed down due to inadequate funding and dwindling political interest, although some survived to the new millennium (Jackson, Sleigh, Li, \& Liu, 2005). But interest in rural health financing continues in China and the NCMS was introduced with important changes. The new insurance scheme draws from the larger population pool (200,000-1 million) of a whole county and is supported by financial commitments from several levels of government (Dummer \& Cook, 2007; Sun et al., 2009).

One question confronting Chinese policy makers is the effect the NCMS has on healthcare providers. Earlier works (Dong, Bogg, Rehnberg, \& Diwan, 1999; Dong, Bogg, Wang, Rehnberg, \& Diwan, 1999; Zhang, Feng, Zhang, \& Zhang, 2003) reported an association between health insurance and over-prescription in rural China. The 
studies were conducted before the introduction of the NCMS and were mostly concerned with township hospitals. Our study takes place after the NCMS began and focuses on prescribing behaviour in village health stations, the level of care below township hospitals. Village health stations are the most easily accessed by farmers and there is at least one in every village. We collected first-hand information in 2005 from a sample of 30 village health stations in Shandong Province, comparing Linyi county (with NCMS) and Qihe county (without NCMS). We are unaware of previous reports on effects of the new medical scheme comparing a county with and without an NCMS.

\section{Methods}

Study setting

Linyi (with NCMS) is a typical agricultural county in Shandong with a total population of 519,300 with $81 \%$ as farmers. The average net income of farmers was 3031 yuan in 2003 (Bureau of Statistics of Linyi County, 2004). In 2003, the infant mortality rate was 12.91 per 1000 live births and the maternal mortality ratio was 37.4 per 100,000 live births.

Qihe county (non-NCMS) was selected for similar geographical, cultural, socio-economic conditions, and healthcare policy and regulation (including drug policy and administrative strategies), but no NCMS operated in it. The total population was 609,100 and $83.9 \%$ were farmers. The average net income of farmers was 3028 yuan in 2003 (Bureau of Statistics of Qihe County, 2003). The infant mortality rate and maternal mortality ratio were 13.89 per 1000 live births and 37.5 per 100,000 live births.

\section{Sampling of village health stations}

A total of 30 village health stations (VHSs) were selected through stratified sampling. All townships in both study counties were already divided by local officials into three tiers of socioeconomic status (SES): high SES, middle SES and low SES townships. In both counties, one township was randomly selected from each of the three SES strata. From each of the six selected townships five villages were randomly chosen. All village health stations in the 30 chosen villages were investigated; the total number of village health stations sampled was 30 because each village had only one village health station. The study was formally approved by the Ethics Committee of the Australian National University, Canberra. In addition, the field research was approved by the Provincial New Cooperative Medical Scheme Office of Shandong, China.

\section{Data collection in village health stations}

Village doctors do not usually keep formal medical records of their patients. In order to obtain information on patient visits, a patient visit record form was designed to collect data on patients' age, sex, NCMS membership, diagnosis, treatment and medical costs. The 30 chief village doctors were asked to record every patient visit on the form, beginning the day after they received the record forms and continuing for two consecutive weeks. These forms were distributed and collected by researchers. The field investigation lasted from the end of March 2005 to the end of April 2005.

\section{Indicators and data analysis}

Village doctors' prescription behaviour was assessed in four aspects:
(1) the number of drugs prescribed per patient visit;

(2) whether the prescription included antibiotics;

(3) the method of drug administration (oral/external or injection);

(4) total medical costs per patient visit.

We compared these indicators between NCMS and non-NCMS village health stations to reflect differences in prescribing behaviour. Within NCMS villages in Linyi, NCMS members and non-NCMS members were compared to reflect the difference in prescribing behaviour for the insured and uninsured. All data were analyzed using SPSS version 12.

\section{Results}

\section{Background of the NCMS in Linyi county}

The NCMS in Linyi began in 2003 with coverage of $93.5 \%$ and rose to $94.6 \%$ in 2004. Per capita funding of the NCMS was 23 yuan (10 yuan from the individual and a total of 13 yuan from various levels of government). Of the total available NCMS funds, 70\% were allocated to inpatient reimbursements and 30\% to outpatient services delivered by township hospitals or village doctors. The NCMS has contractual agreements with various health facilities (e.g. village health stations) relating to the payment system and the delivery of health services.

NCMS benefits cover pharmaceuticals, outpatient services in village health stations, outpatients and inpatients in township hospitals and in county or higher level hospitals. Patients at village health stations receive a $20 \%$ discount for medical expenses during each visit, and village doctors keep a record of discounts given which are then inspected by NCMS officials. The NCMS pays village health stations an annual capitation of 3 yuan per insured villager. Capitation payments account for about half the NCMS funds allocated for outpatient services with the rest going to township hospitals. Hospital outpatients also directly pay for medical services at prices discounted at $20 \%$. Inpatients receive $20-75 \%$ reimbursement for medical expenses, higher reimbursement rates for higher expenses; there is a ceiling of 20,000 yuan per person per year.

\section{Description of NCMS and non-NCMS patients at 30 village health stations}

In 2005, we recorded 2271 patient visits in two weeks at the 30 village health stations: 1025 at NCMS and 1246 at non-NCMS VHSs. There were no significant differences in sex distribution, visit status or age group distribution between patients in NCMS and non-NCMS villages (Table 1 ). The average age of patients was 37.3 years in NCMS villages and 35.5 years in non-NCMS villages. Generally, about half the patients were females, and 70\% were making a first visit for the health condition treated.

As for the NCMS villages in Linyi, 92.5\% of patient visits were NCMS members. There were no significant differences in sex distribution and visit status between the insured and uninsured, but age group distribution was significantly different (Table 1). Uninsured patients were generally younger than the insured, suggesting that there might be adverse selection in joining the NCMS in Linyi county.

\section{Drug prescribing behaviour of village doctors}

\section{Number of drugs per patient visit}

NCMS village health stations tended to prescribe and sell more drugs than the non-NCMS (Table 2). NCMS village doctors prescribed an average number of 4.6 drugs per patient visit, and 
Table 1

Patients at 30 village health stations in Linyi and Qihe counties, 2005.

\begin{tabular}{|c|c|c|c|c|}
\hline & \multicolumn{3}{|c|}{$\begin{array}{l}\text { Linyi county: NCMS village } \\
\text { health stations }\end{array}$} & \multirow[t]{2}{*}{$\begin{array}{l}\text { Qihe county: non-NCMS } \\
\text { village health stations }\end{array}$} \\
\hline & Members & Non-members & Total & \\
\hline \multicolumn{5}{|l|}{$\overline{\text { Sex }}$} \\
\hline Male & $452(47.7)$ & $34(44.2)$ & $486(47.4)$ & $619(49.8)$ \\
\hline Female & $496(52.3)$ & $43(55.8)$ & $539(52.6)$ & $624(50.2)$ \\
\hline Total & $948(100.0)$ & $77(100.0)$ & 1025 (100) & $1243(100)$ \\
\hline \multicolumn{5}{|l|}{ First visit } \\
\hline Yes & $578(70.1)$ & $57(74.0)$ & $635(70.4)$ & $780(68.2)$ \\
\hline No & 247 (29.9) & $20(26.0)$ & 267 (29.6) & 363 (31.8) \\
\hline Total & $825(100.0)$ & $77(100.0)$ & $902(100.0)$ & $1143(100.0)$ \\
\hline \multicolumn{5}{|l|}{ Age group } \\
\hline $0-4$ & $70(7.6)$ & $9(12.3)$ & 79 (7.9) & $108(8.7)$ \\
\hline $5-14$ & $112(12.1)$ & $14(19.2)$ & $126(12.6)$ & $196(15.8)$ \\
\hline $15-34$ & $232(25.1)$ & $15(20.5)$ & $247(24.8)$ & $303(24.4)$ \\
\hline $35-59$ & $335(36.3)$ & $30(41.1)$ & 365 (36.6) & $436(35.1)$ \\
\hline $60+$ & 175 (18.9) & $5(6.8)$ & $180(18.1)$ & $198(16.0)$ \\
\hline Total & $924(100.0)$ & $73(100.0)$ & $997(100.0)$ & $1241(100.0)$ \\
\hline
\end{tabular}

Note: distributions of sex, first visit and age group were similar for Linyi and Qihi $(p>0.05)$. Information for some patients was missing. Therefore, the total number of patients for each measured indicator varies a little. Overall, patient visits totalled 2271, 1025 in Linyi county and 1246 in Qihe county. Numbers in brackets are percentages.

$45.6 \%$ of patient visits had five or more kinds of drugs. Non-NCMS village doctors averaged 3.1 drugs per patient visit, and $13.5 \%$ of prescriptions contained five or more drugs. The tendency of doctors in NCMS villages to prescribe more drugs was statistically significant, whether measured as the average number of drugs per patient visit or as the proportion of patient visits given five or more drugs.

At the NCMS village health stations in Linyi, the village doctors prescribed more drugs to the insured patients than to the uninsured. The average number of drugs dispensed for the insured was 4.7, significantly higher than 3.9 for the uninsured. For NCMS members, $47.0 \%$ of patient visits resulted in five or more kinds of drugs being prescribed, compared to $29.9 \%$ for non-NCMS members (Table 2).

\section{Antibiotics}

For NCMS village doctors, $72.4 \%$ of prescriptions included antibiotics (Table 3), significantly higher than $59.3 \%$ for non-NCMS. The difference in the proportion of prescriptions containing three or more kinds of antibiotics between NCMS and non-NCMS village doctors (5.3\% against 3.6\%) was also statistically significant.

For the NCMS village health stations in Linyi, more than $70 \%$ of patient visits by both the insured and uninsured resulted in prescriptions with antibiotics. The frequency of prescribing three or

Table 2

Prescriptions at 30 village health stations in Linyi and Qihe counties: number of drugs per patient visit, 2005.

\begin{tabular}{lcccc}
\hline $\begin{array}{l}\text { Number of drugs } \\
\text { per patient visit }\end{array}$ & $\begin{array}{l}\text { Linyi county: NCMS } \\
\text { village health stations }\end{array}$ & \multirow{2}{*}{$\begin{array}{l}\text { Qihe county: Non-NCMS } \\
\text { village health stations }\end{array}$} \\
\cline { 2 - 3 } & $\begin{array}{l}\text { NCMS } \\
\text { member }\end{array}$ & Non-member & Total & \\
\hline 0 & $0.2 \%$ & $0.0 \%$ & $0.2 \%$ & $0.3 \%$ \\
1 & $4.3 \%$ & $2.6 \%$ & $4.1 \%$ & $8.2 \%$ \\
2 & $12.7 \%$ & $29.9 \%$ & $14.1 \%$ & $29.0 \%$ \\
3 & $25.2 \%$ & $23.4 \%$ & $25.1 \%$ & $35.6 \%$ \\
4 & $10.6 \%$ & $14.3 \%$ & $10.9 \%$ & $13.4 \%$ \\
$\geq 5$ & $47.0 \% *$ & $29.9 \% *$ & $45.6 \% * *$ & $13.5 \% * *$ \\
Total & $100.0 \%$ & $100.0 \%$ & $100.0 \%$ & $100.0 \%$ \\
Mean & $4.7^{* * *}$ & $3.9^{* * *}$ & $4.6^{* * * *}$ & $3.1^{* * * *}$ \\
\hline
\end{tabular}

Pair-wise 2-tailed tests: ${ }^{*} p<0.05 ;{ }^{* *} p<0.001,{ }^{* * *} p<0.01,{ }^{* * * *} p<0.001$
Table 3

Prescriptions at 30 village health stations in Linyi and Qihe counties: number of antibiotics per patient visit, 2005.

\begin{tabular}{lllll}
\hline \begin{tabular}{l} 
Number of antibiotics $\begin{array}{l}\text { linyi county: NCMS village } \\
\text { per patient visit }\end{array}$ \\
\cline { 2 - 4 }
\end{tabular} & $\begin{array}{l}\text { LCMS } \\
\text { health stations }\end{array}$ & $\begin{array}{l}\text { Qihe county: Non-NCMS } \\
\text { village health stations }\end{array}$ \\
\cline { 2 - 3 } No antibiotics & $27.8 \%$ & $23.4 \%$ & $27.6 \%$ & $40.7 \%$ \\
With antibiotics & $72.2 \%$ & $76.6 \%$ & $72.4 \% *$ & $59.3 \% *$ \\
1 & $49.1 \%$ & $57.1 \%$ & $49.7 \%$ & $40.1 \%$ \\
2 & $17.5 \%$ & $18.2 \%$ & $17.5 \%$ & $15.5 \%$ \\
$\geq 3$ & $5.6 \% * *$ & $1.3 \% * *$ & $5.3 \% * * *$ & $3.6 \% * *$ \\
\hline
\end{tabular}

Pair-wise 2-tailed tests: ${ }^{*} p<0.001 ;{ }^{* *} p=0.05 ;{ }^{* * *} p<0.05$.

more antibiotics was $5.6 \%$ for the insured and $1.3 \%$ for the uninsured (Table 3), but this difference was of borderline statistical significance owing to the small number of uninsured recorded.

\section{Method of drug administration}

The method of drug administration is an important indicator of service quality because of the problem of unsafe injections (Zhuo, Sleigh, \& Wang, 2002). In both counties combined, $60.2 \%$ of patient visits resulted in injections; and overall $42.6 \%$ of patients received intravenous drug administrations. The method of drug administration used by NCMS and non-NCMS village doctors was significantly different (Table 4 ). More patients (65.1\%) in NCMS village health stations received injections than patients (56.3\%) in nonNCMS health stations. Intravenous injections were more frequent in NCMS village health stations ( $45.2 \%$ of patient visits) than in nonNCMS health stations (33.6\% of patient visits), also a significant difference.

For the NCMS village health stations in Linyi, the method of drug administration for insured and uninsured patients was different (Table 4). More insured patients than uninsured (65.7\% against $58.4 \%$ ) were administered by injections. Intravenous administration occurred more often for the insured than the uninsured $(46.1 \%$ against $35.1 \%$ ).

\section{Total medical costs per patient visit at village health stations}

The average total medical costs per patient visit were significantly different between NCMS and non-NCMS village health stations. In NCMS villages they averaged 18.1 yuan before the $20 \%$ discount, 3.0 yuan higher than the costs for non-NCMS villages $(p<0.001)$. Pre-discount drug costs in the NCMS villages averaged

Table 4

Methods of drug administration at 30 village health stations in Linyi and Qihe counties, 2005.

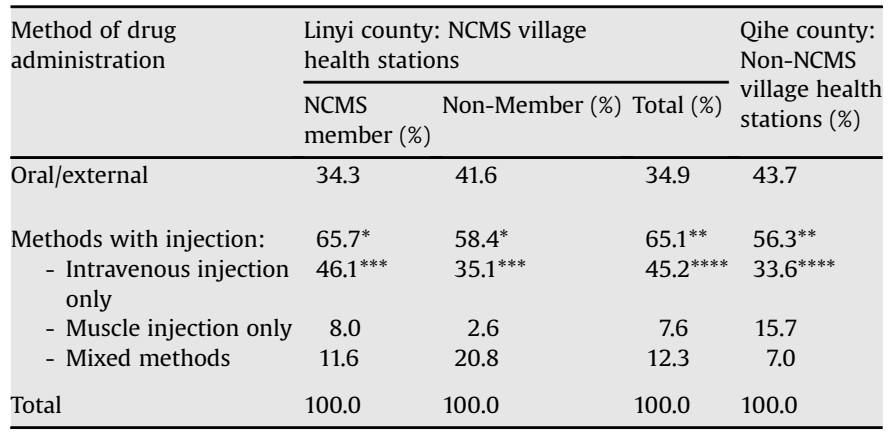

Pair-wise 2-tailed tests: ${ }^{*} p>0.05 ;{ }^{* *} p<0.001 ;{ }^{* * *} p<0.05 ;{ }^{* * * *} p<0.001$. 
16.9 yuan, 2.6 yuan higher than in the non-NCMS villages $(p<0.001)$.

For the NCMS village health stations in Linyi, average total medical costs for the insured and uninsured were significantly different $(p<0.001)$ : the insured averaged 18.7 yuan (prediscount) compared to 11.3 yuan for the uninsured. The difference in average total drug costs for the insured (17.4 yuan pre-discount) and uninsured (10.7 yuan) was of similar magnitude $(p<0.001)$.

\section{Discussion}

Our comparison of Shandong village health stations with and without health insurance suggests a positive relationship between health insurance and opportunistic behaviour of health providers. The effect of the NCMS was to exaggerate the problem of overprescription and excessive injections that was already occurring in rural Shandong. The rural study by Zhang et al. (2003) on township hospitals conducted before implementation of the NCMS also reported over-prescription and that $68.3 \%$ of the prescriptions contained antibiotics. Overuse of antibiotics can lead to antimicrobial resistance and overuse of injections runs the risk of unsafe needles that can increase the transmission of AIDS, hepatitis B and C, and other blood-borne diseases (Zhuo et al., 2002). Furthermore, multidrug use may increase the risk of undesirable drug interactions.

We found prescribing malpractices in all the 30 study villages. In our study of both NCMS and non-NCMS villages, the average number of drugs prescribed per patient visit was 3.8. This was higher than the average of 2.2 per patient visit found in a study of 17 developing countries where the highest recorded was 3.8 found in Indonesia and Nigeria (Pavin, Nurgozhin, Hafner, Yusufy, \& Laing, 2003). Thus, our study highlights the problem in rural China as among the world's most severe. Indeed, we even found that about $28.0 \%$ of all patient visits were prescribed five or more different kinds of drugs (one common definition of polypharmacy); the highest number was 15 drugs for a single patient visit. Furthermore, $65.2 \%$ of our patients were prescribed antibiotics and $61.2 \%$ given injections, higher than the $43.1 \%$ and $28.7 \%$, respectively, found in a study of primary care physicians in rural Uzbekistan (Pavin et al., 2003). Also, in our study about $20 \%$ of patients had two or more kinds of antibiotics. The implication is that irrational drug use is common in rural China.

We consider Linyi to be representative of Shandong because its economy ranks in the middle amongst Shandong's counties. Funding resources available to Linyi's NCMS were around the middle level for the seven Shandong pilot counties. The benefits package of Linyi's NCMS was similar to most other counties not only in Shandong but also in other parts of China, covering pharmaceuticals, outpatient services in village health stations, and hospital outpatient and inpatient services.

Qihe was chosen for comparison because of similarities to Linyi, documented for population size, proportion of farmers, income and maternal and child mortality. We expect disease patterns at primary care level would also be similar. As well, we used a large 2stage random sample (30 villages and 2271 patient visits), stratified into three SES categories. Qihe and Linyi samples were similar for age, sex and visit status. We conclude that differences noted for prescribing practices are not likely to reflect sampling bias.

\section{Explaining over-prescribing behaviour of Chinese village doctors}

Apart from effects of the NCMS to be discussed later, there are important underlying factors that could influence village doctors' prescribing behaviour from the demand and supply side of medical care.

\section{Demand side}

The patient's income, age, sex, occupation, insurance coverage and cultural background may influence willingness to accept a particular drug or a method of drug administration, which in turn can influence the village doctor's prescribing behaviour. Farmers often ask for injections because they believe injections help them recover sooner. To meet patient demand, village doctors often prescribe multiple medications for simple, self-limited illnesses (such as colds) and use intravenous antibiotics for upper respiratory tract infections.

\section{Supply side}

For China, we think that over-prescription and overuse of injections are more likely to be initiated by village doctors themselves. There are two main reasons.

First, the rural healthcare market provides strong incentives for village health stations to sell drugs. Among China's total 551,600 village health stations in $2004,30.2 \%$ were privately owned (Centre for Health Statistics and Information Ministry of Health, 2005). Even those owned by village committees or jointly with village doctors are mostly private. Without financial help from the government or the village collective, health workers are expected to make a living from selling drugs and fee-for-service payments. Most village doctors earn money from only a limited number of services such as injections, acupuncture, and massage. Thus, village doctors rely heavily on selling drugs; they are allowed to sell drugs at prices marked up from wholesale prices, to make a profit. Our results imply that China's drug mark-up policy by which village doctors sell drugs to make a living should be changed.

Second, inadequate training and medical knowledge of village doctors could lead to irrational drug use. A few doctors are former "barefoot doctors" of the early 1980s with 6-12 months' training as paramedics, but most now have three years' training. However, a substantial proportion still lack the medical knowledge to engage in rational prescribing and proper administration of drugs. Our results imply village doctors urgently need more training on rational drug use.

\section{Effect of NCMS on village doctors' prescribing behaviour}

Our results support the findings of earlier studies (Dong, Bogg, Rehnberg et al., 1999; Dong, Bogg, Wang et al., 1999) that reported an association between health insurance and prescribing behaviour. We found that incentives for over-prescribing did not decline with introduction of the NCMS. On the contrary, NCMS village health stations tend to over-prescribe more often than non-NCMS. Indeed, the typical extra pre-discount charge per visit for NCMS patients (about 3 yuan) is approximately equal in value to the $20 \%$ discount offered to insured villagers for outpatient services. So NCMS-insured patients pay about the same amount per visit as non-insured patients (15 yuan) but receive more drugs, antibiotics and injections. Thus, NCMS doctors offset the discount by providing more services and drugs. Similar behaviour in other treatment settings in China has been noted. For example, Henan Province TB patients given free anti-tuberculosis treatment with a value of about 500 yuan were found to have paid a similar amount for other non-TB drugs and supplements supplied by the doctor treating their TB (Jackson, Sleigh, Wang, \& Liu, 2006).

A pro-active policy on healthcare purchasing could improve the quality of village doctor services. The NCMS could define quality requirements in the contracts, like "managed care" in the USA. Then the Chinese health providers would be forced to improve service quality to meet the contract requirements. But we also need to reform the existing incentives for selling drugs across the rural 
health system. This is not impossible as the healthcare regulatory institutions are themselves in a transition (Fang, 2008).

\section{Conclusions}

The introduction of China's newest rural health insurance scheme since 2003 has adversely influenced prescribing behaviour in village health stations, but irrational drug prescription also occurred in those health stations without insurance. Health service quality and drug safety in the rural areas should be a public concern. We draw two conclusions.

First, the NCMS seemed to encourage village doctors to prescribe even more drugs and antibiotics, and be more likely to use injections. The pre-discount cost per patient visit in NCMS villages was higher than in non-NCMS villages, and even within the NCMS village health stations there was a higher average prediscount fee for the insured.

Second, irrational drug prescription behaviour also occurred in village health stations without the NCMS. The incentive to sell more drugs and expensive drugs existed because of (a) government policy on drug sales and (b) the private ownership of village health stations which are left to run without government subsidies.

We have three policy recommendations. First, the NCMS should be designed to exert a stronger financial influence over the health providers to improve service quality and contain costs. Second, to counter irrational drug use there should be improved medical training for village doctors. Third, the present systemic incentives for selling and over-prescribing drugs in village health stations should be removed through a radical reform of the rural health system. If this is carried out, we think the NCMS can work for the good of the rural population. Furthermore, a recent review of numerous reports on polypharmacy in developed countries points to its prevalence amongst the aged, with poor compliance, therapeutic duplication, drug interaction and adverse effects (Gorard, 2006). China's population is rapidly ageing so over-prescribing needs urgent attention now to prepare for challenges ahead.

\section{References}

Bureau of Statistics of Linyi County. (2004). Handbook of Linyi statistics 2003. Linyi: Bureau of Statistics of Linyi.

Bureau of Statistics of Qihe County. (2003). Qihe Guang Hui 50 Nian (19492002). [Brilliant fifty years 1949-2002 in Qihe]. Qihe: Bureau of Statistics of Qihe.

Centre for Health Statistics and Information Ministry of Health. (2004). China health statistics digest 2004. Beijing: Chinese Ministry of Health.

Centre for Health Statistics and Information Ministry of Health. (2005). China health statistics digest 2005. Beijing: Chinese Ministry of Health.

Dong, H., Bogg, L., Rehnberg, C., \& Diwan, V. (1999). Association between health insurance and antibiotics prescribing in four counties in rural China. Health Policy, 48, 29-45.

Dong, H., Bogg, L., Wang, K., Rehnberg, C., \& Diwan, V. (1999). A description of outpatient drug use in rural China: evidence of differences due to insurance coverage. International Journal of Health Planning and Management, 14, 41-56.

Dummer, T. J. B., \& Cook, I. G. (2007). Exploring China's rural health crisis: processes and policy implications. Health Policy, 83, 1-16.

Fang, J. (2008). The Chinese health care regulatory institutions in an era of transition. Social Science \& Medicine, 66(4), 952-962.

Gorard, D. A. (2006). Escalating polypharmacy. Quarterly Journal of Medicine, 99, 797-800.

Jackson, S., Sleigh, A. C., Li, P., \& Liu, X. (2005). Health finance in rural China: low premium insurance compared to the out-of-pocket system. The China Quarterly, 181, 137-157.

Jackson, S., Sleigh, A. C., Wang, G.-J., \& Liu, X.-L. (2006). Poverty and the economic effects of TB in rural China. International Journal of Tuberculosis and Lung Diseases, 10(10), 1104-1110.

Liu, Y. (2004). Development of the rural health insurance system in China. Health Policy and Planning, 19(3), 159-165.

Meng, Q., Liu, X., \& Shi, J. (2000). Comparing the services and quality of private and public clinics in rural China. Health Policy and Planning, 15(4), 349-356.

Pavin, M., Nurgozhin, T., Hafner, G., Yusufy, F., \& Laing, R. (2003). Prescribing practices of rural primary health care physicians in Uzbekistan. Tropical Medicine and International Health, 8(2), 1889-1890.

Sun, X., Jackson, S., Carmichael, G., \& Sleigh, A. C. (2009). Catastrophic medical payment and financial protection in rural China: evidence from the New Cooperative Medical Scheme in Shandong Province. Health Economics, 18(1), $103-119$.

Zhang, X., Feng, Z., Zhang, L., \& Zhang, J. (2003). Analyze quality of prescription of township hospitals in depressed areas. Chinese Rural Health Management (12), 33-35.

Zhuo, J., Sleigh, A. C., \& Wang, H. (2002). Unsafe injection and HIV transmission in Guangxi, China. Chinese Medical Journal, 115(6), 960-963. 